\title{
3D VIRTUALIZATION OF AN UNDERGROUND SEMI-SUBMERGED CAVE SYSTEM
}

\author{
E. Nocerino ${ }^{1,2}$, F. Menna ${ }^{3,4}$, E. Farella ${ }^{4}$, F. Remondino ${ }^{4}$ \\ ${ }^{1}$ LIS, I\&M Team, Aix-Marseille Universite, Polytech Luminy, 13288 Marseille, France -erica.nocerino@univ-amu.f \\ ${ }^{2}$ Institute of Theoretical Physics, ETH Zurich, 8093 Zurich, Switzerland - erican@phys.ethz.ch \\ ${ }^{3}$ COMEX SA - Innovation Department, COMEX, 36 bd de l'Océan - CS 80143 - 13275 Marseille, France - f.menna@comex.fr \\ 4 3D Optical Metrology (3DOM) unit, Bruno Kessler Foundation (FBK), Trento, Italy -
}

(fmenna, efarella, remondino)@fbk.eu, http://3dom.fbk.eu

\section{Commission II, WG II/8}

KEY WORDS: Underwater photogrammetry, semi-submerged, laser scanning, virtual reality, stereo system, virtualization

\begin{abstract}
:
Underwater caves represent the most challenging scenario for exploration, mapping and 3D modelling. In such complex environment, unsuitable to humans, highly specialized skills and expensive equipment are normally required. Technological progress and scientific innovation attempt, nowadays, to develop safer and more automatic approaches for the virtualization of these complex and not easily accessible environments, which constitute a unique natural, biological and cultural heritage.

This paper presents a pilot study realised for the virtualization of 'Grotta Giusti' (Fig. 1), an underground semi-submerged cave system in central Italy. After an introduction on the virtualization process in the cultural heritage domain and a review of techniques and experiences for the virtualization of underground and submerged environments, the paper will focus on the employed virtualization techniques. In particular, the developed approach to simultaneously survey the semi-submersed areas of the cave relying on a stereo camera system and the virtualization of the virtual cave will be discussed.
\end{abstract}

\section{INTRODUCTION}

Exploration, documentation and mapping of underwater environment is one of the biggest open challenges for science and engineering. While it is undoubtful that there still is room for improvements towards more and more efficient 3D mapping and modelling approaches for 'terrestrial' scenarios, challenges are even more crucial when it comes to the underwater environment. It is estimated that about $80 \%$ of the ocean is unexplored (NOAA, 2018) and underwater caves represent probably the most fascinating, complex and dangerous type of underwater exploration.

Underwater caves result from a combination of geologic processes, events and climatic related changes that led to development of ecosystems often characterized by a labyrinthic network of galleries, narrow passages and large voids that may feature spectacular structures like stalactites and stalagmites. The genesis of such magnificent environment may be the result of processes developed over the course of million years. The natural and mystic beauty of such environments was recognized since long time, being also used by ancient civilizations for sacrificial offerings or aquatic cemeteries, such as the case of cenotes in the Maya civilization (Leshikar-Denton et al., 2016). Dark marine habitats, such as submarine caves, are often characterized by a food-limited condition, but still harbour remarkable biodiverse marine life (Bussotti et al., 2018; Rosso et al., 2018).

As such, submerged and semi-submerged caves, filled with fresh and saltwater, constitute a unique heritage which needs special approaches for its 3D digitization and preservation. Despite being unique natural beauties, underwater cave systems are also very dangerous places, most of the time accessible only to specially trained and experienced divers. a)

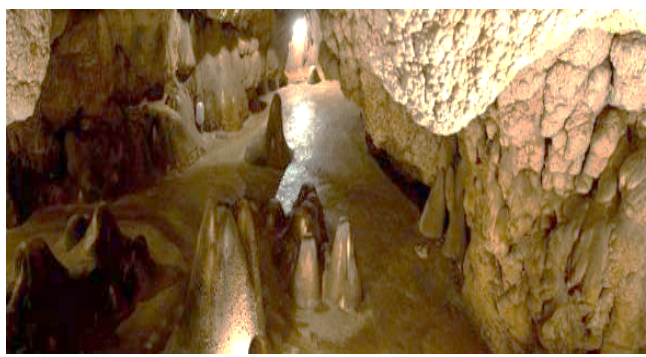

b)

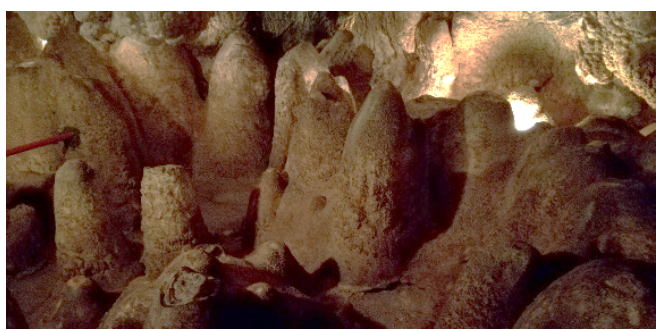

c)

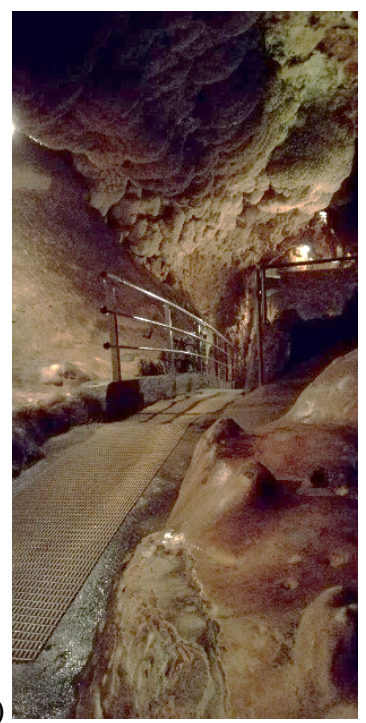

d)

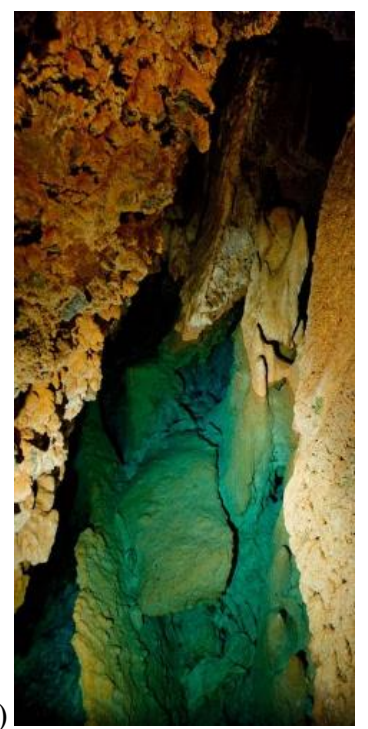

Figure 1. Grotta Giusti cave system: underground narrow passages (a, b); corridor from 'Sala Vestibolo' to 'Lago del limbo' (c) and the main entrance to the underwater cave system (d). 
Underwater caves are among the most difficult and dangerous structures to be surveyed and modelled in 3D. For this reason, most cave systems are unmapped or just few manual sketches, accompanied by simplified topographic surveys, are available. Specialized cave trained divers have for long used simplified methods of topographic surveying based on a combination of dive computer depth meter, tape ruler distance and a compass to record the cave system in form of sketches (Lauritzen et al., 1985). This simple but effective method has allowed the exploration of very complex cave systems for many years and is still the most commonly employed approach today because of the strict safety protocols of scientific cave diving requiring minimal equipment and simplicity of operations (Iliffe and Bowen, 2001). Photographs and video have also been used as additional documentation material. Because of safety concerns, the evolution of techniques has certainly followed the direction of vision- and acoustic-based digital imaging technologies, for example with small Remotely Operated Vehicles - ROVs or Autonomous Underwater Vehicles - AUVs (Clark et al., 2008; White et al., 2010; Gerovasileiou et al., 2013; Mallios et al., 2016).

This paper will focus on the feasibility study carried out for the virtualization of an underground semi-submerged cave system called 'Grotta Giusti' (Fig. 1). The underwater cave is located in Tuscany (central Italy) and is currently part of a thermal resort. The cave system has the characteristic of a fault, and part of it can be accessed and visited by recreational divers through a special program of visits managed by an association of speleological guides (http://www.grottagiustidiving.com/). Grotta Giusti is the European biggest cave filled with warm water. Due to the geological characteristics of the cave system, conditions may significantly vary during the year making the access to the cave more difficult or even impracticable, after very dry winter seasons. The cave alternates parts completely submerged with crystal clear thermal water with areas that are dry and parts that are partially filled with water.

The contribution of this paper is three-fold: (i) to provide a detailed overview of virtualization approaches for underground environments, (ii) to present the developed approach to simultaneously survey the semi-submerged areas of the cave based on a stereo camera system, and (iii) to present the first results of the virtualization process of Grotta Giusti cave system.

\section{VIRTUALIZATION OF CULTURAL HERITAGE}

In recent years, the concept of $\mathrm{CH}$ has gradually developed: from an obstacle to economic growth to a precious resource, it has evolved into a key element in supporting and promoting a sustainable development, which embraces different aspects, i.e. environment, society and economy (Tommasi et al., 2019). These views correspond to models called respectively $\mathrm{CH}$ management 1.0 and 3.0 according to Gustafsson (2015). The new paradigm requires an interdisciplinary and integrated approach, to properly understand and exploit the value of the heritage asset and realise the sought sustainable development. The full lifecycle of modern $\mathrm{CH}$ entails four phases. i.e. knowledge, use, communication and management (Apollonio et al., 2017), which should be integrated into a comprehensive platform, making available all the useful information to the involved actors.

Central in the new concept of $\mathrm{CH} 3.0$ is the virtualization of the asset. Data virtualization has been defined as the process of aggregating data from different sources of information to develop a single, logical and virtual view of information so that it can be accessed by front-end solutions (Techopedia). This definition can be extended to $\mathrm{CH}$, where the virtualization process might be synthetized as in Fig. 2.

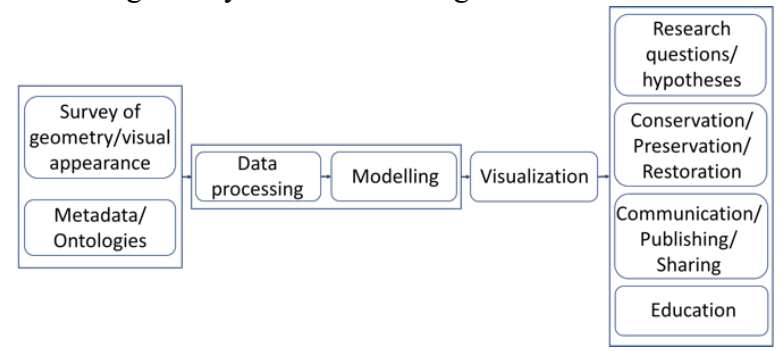

Figure 2: The virtualization process.

The virtualization process of a $\mathrm{CH}$ asset includes a first step of data gathering (corresponding to the knowledge phase from Tommasi et al., 2019). It consists in the survey of the geometric and visual appearance of the asset and collection of ancillary information, collected in reach metadata ontologies, which provide the importance of the asset, define its uniqueness, allowing for a comprehensive knowledge and make the cultural resource accessible. Ontologies represent one of the main SemanticWeb infrastructure elements; they allow the sophisticated, extended and rich expression of meanings and the ability of reasoning (Stasinopoulou et al., 2007).

Data processing and modelling produce the digital version of the assets. The two steps can be considered nowadays straightforward and almost fully automatic, when data come from a unique source and the asset geometrical form and visual appearance are simple. However, when the integration of different techniques is required, or the scene is particularly complex, then usually ad-hoc processing strategies are developed.

Visualization of the digitised $\mathrm{CH}$ is also of paramount importance and usually preparatory for the successive steps in the virtualization process (Fig. 2). Latest researches affirm that communication tools based on a multimedia approach, i.e. the use of new and combined media, enhances the diffusion and exploitation of $\mathrm{CH}$ (Bekele et al., 2018). Augmented (AR), virtual (VR) and mixed-reality technologies are exploited for a number of different purposes, including education, exhibition enhancement, exploration, reconstruction, and virtual museums (Bekele et al., 2018). However, despite the remarkable developments in technology, a gap still exists between the attainable finest geometrical details and the possibility of handling it in an effective way. To efficiently deal with the two major issues of large data handling, i.e. memory efficiency and rendering performance (Bartz, 2003), several techniques for the automatic simplification of highly detailed models into faithful approximations using fewer polygons have been developed (Garland, 1999). The adoption of a multi-resolution data structure allows to efficiently perform view-dependent and progressive refinement of the geometry (and texture) during visualization (Potenziani et al., 2015).

\section{SURVEYING AND REPRESENTATION METHODS FOR UNDERWATER CAVES}

Virtualization represents a key resource for complex or not easily accessible environments. Still today, the effective surveying and visualization of complex underground, narrow and dark environments are still challenging. 


\subsection{D Surveying of complex underground scenarios}

3.1.1 Dry underground structures: Traditionally, cave surveying has been performed using distance and angular measurements and field sketches, with a great deal of artistic imagination being added (The Wakulla 2 expedition, 1988) to produce mainly $2 \mathrm{D}$ maps.

Similarly to other research domains, in the last years digital 3D mapping technologies have emerged also in cave surveying. Terrestrial laser scanners (TLSs) have been extensively used in underground environments for a wide spectrum of applications, ranging from archaeology to geomorphology, from palaeontology/paleoclimatology to ecology/biology and visualization and education (Fabbri et al., 2017; Mohammed Oludare \& Pradhan, 2016). Examples of photogrammetric surveying have also been reported in the literature, in comparison (Pukanská et al., 2017) or combination with TLS (De Waele et al., 2018; Rodríguez-Gonzálvez et al., 2015). Recently, fisheye lenses have been successfully employed in natural (Alessandri et al., 2019) and man-made narrow spaces (Perfetti et al., 2017). However, portable mobile mapping systems (Sammartano \& Spanò, A., 2018; Zlot \& Bosse, 2014) or a combination of 3D techniques (Farella et al., 2016) have proved to be very effective surveying methodology for underground structures.

3.1.2 Underwater caves: Surveying underwater cave is even more critical. Cave diving requires highly specialized skills, intensive training, rigorous safety procedures and expensive diving equipment. Moreover, the deeper the diver goes, the greater the technical complexity of diving operations (i.e. use of several gas mixes and/or longer time needed for decompression) which in turn corresponds to bigger safety risks associated. Indeed, as the depth and pressure increase, the inert gasses contained in the air and breathed by divers dissolve into their body tissues and are released as bubbles as the pressure diminishes when ascending to the surface. The limitations of the amount of breathable air and, more importantly, the demand of keeping decompression time as low as possible do not permit to spend long time especially when exploring very deep underwater environments.

Traditionally, underwater caves were surveyed using a continuous line with knots, also called stations at fixed intervals, because the use of fiberglass tape was considered an entanglement hazard underwater (am Ende, 2001). By counting the knots, the distance was measured. The azimuth between the stations was measured with a compass and the depth with the diver's depth gauge. Starting from this basic information, 2D maps were usually derived. However, due to their complex 3D shape, a full understanding of cave morphology and its correlation with other parameters such as hydrologic and geologic variables is hard to achieve with a 2D representation.

Kincaid (2000) developed a method to produce 3D models of caves from simple measurements of cross-sectional profiles of the cave, including the top, bottom, left and right wall and the locations of each data measurement. Using $2 \mathrm{D}$ and $3 \mathrm{D}$ gridding methods, the 3D model of the outer surface was derived, incorporating not only the topography of the conduit but other data, such as temperature, water velocity, $\mathrm{pH}$, dissolved oxygen, and ion concentrations. Gerovasileiou et al. (2013) extended the classic measurement approach with the use of handheld echosounder employed to measure from station points the radial distance to the walls at different angles.

The Wakulla 2 project (am Ende, 2001) probably represents one of most pioneering and challenging cave missions. The Wakulla springs is located in Florida; it is a very complex system, with different tunnels and branches, extending in total more than 20 $\mathrm{km}$. To reduce the decompression time in water, a deployable personnel transfer capsule (PTC), placed in the spring pool above the cave's mouth, was used to bring the divers from depth directly to a decompression chamber. A special dive scooter was designed with batteries lasting for nearly $20 \mathrm{~km}$ and a high intensity discharge (HID) lamp was realized to produce a powerful and narrowly focused beam in the underground gloom that was $30-\mathrm{m}$ wide for long distances. Special radio transmitters able to penetrate the rock of the cave as far as $500 \mathrm{~m}$ were developed and used to define a reference system into the cave, connected to known locations at the surface measured with GPS. The most distinguished piece of equipment from a surveying point of view was the so-called digital wall mapper (DWM). Thirty-two sonar transducers were spirally arrayed around the nose of the 2-m long, $150 \mathrm{~kg}$ instrument. Data from an Inertial Measurement Unit (IMU) were integrated to estimate the position and orientation of the DWM inside the cave system.

Drap et al. (2014) fused data from a static acoustic camera and a photogrammetric system with three synchronized digital cameras to produce a multi-resolution dense 3D model of an underwater cave off the coast of Marseilles.

A pure imaged-based approach was proposed by Weidner (2017), who employed a stereo camera with an illumination source. The produced illumination cone was used to infer the shape of the cave in a stereo pair and the motion between stereo pairs is then estimated to produce a 3D model of the cave.

Recently, increasing efforts have been devoted in the investigation of autonomous systems for underwater cave exploration and mapping. Mallios et al. (2016) presented experiments conducted in an underwater cave complex using an autonomous underwater vehicle (AUV), equipped with two acoustic sonar and optical sensors. Optical sensors were only used as ground truth to check a simultaneous localization and mapping (SLAM) algorithm based on acoustically sensed data. Rahman et al. (2018) developed and tested in different underwater environments, included a submerged cave a SLAM approach integrating data from acoustic, visual, inertial and depth sensors. Richmond et al. (2018) designed a compact, highly manoeuvrable autonomous vehicle with real-time mapping capabilities.

3.1.3 Semi-submerged environments: The researches so far discussed aimed at surveying and modelling a full submerged environment. In the contrary, Moisan et al $(2015,2017)$ developed a method to fully survey a semi flooded tunnel. In the previous version (Moisan et al, 2015), they employed a terrestrial laser scanner and sonar combined statically for the above-the water and underwater part, respectively. In the dynamic version (Moisan et al, 2017), photogrammetry was used for surveying the above-water part, the vault and side walls of the tunnel, as well as for estimating the trajectory of the boat and aligning the sonar profiles to form the 3D model of the underwater part.

\subsection{Representation}

Since the 18th century, the topic of the representation of hidden and hardly accessible passages involved explorers and cave surveyors, who would produce drawings not only technical but also descriptive (Mattes, 2015). The adopted representation techniques would reflect the different interests in the underground mapping: from one side, more technical plans would support, for example, the governmental needs of exploration and documentation of underground spaces, as well as the growing scientific interests for unexplored natural environments; on the other side, more communicative and allegorical drawings would attract explorers and tourists. Still today, documentation and visualization of caves aims to combine technical and illustrative aspects: if the progress of 3D modelling 
techniques have increased the level of accuracy and completeness of the technical documentation, virtual reality technologies enhance the communicative power of 3D representations. Digital and fully explorable 3D models allow overcoming the main limitations of 2D traditional maps, which are hard to interpret, especially by non-experts. In fact, traditional drawings can only partially convey the full knowledge needed to understand the represented environment. This loss of information is especially relevant when dealing with irregular and complex assets/scenes. In such cases, a more realistic and complete visualization of both geometry and colour information can be only achieved through immersive navigation within the virtualized environment.

\section{VIRTUALIZATION OF GROTTA GIUSTI}

Up today, Grotta Giusti is virtualized through a collection of 2D maps (e.g. Fig. 3). The drawings are based on distance, azimut and depth measurements acquired by the Grotta Giusti diving center (http://www.grottagiustidiving.com) and are the only representation currently available to the public. The names of the different parts of the cave system are inspired to the 'Divine Comedy' by Dante Alighieri.

\subsection{D Survey and modelling}

Grotta Giusti is a distinctive setting, characterized by high humidity and warm temperatures that can significantly vary within the cave complex. This required a period for the equipment to acclimatise both at the arrival and at each repositioning of the instruments within the cave. Indeed, moisture represented a major issue, both for the laser scanner and cameras as the relative humidity, close to $100 \%$, causes condensation phenomena on the outer surface of the optics.

To speed up the surveying step within the virtualization process of the cave, laser scanning and photogrammetry were employed simultaneously: TLS for the dry entrance room ('Sala Vestibolo' in Fig. 4) and photogrammetry for the semi-submerged parts of the cave and for those areas accessible only after diving (i.e. siphons). In the following TLS results in the 'Sala Vestibolo' and photogrammetric results in the 'Lago del Limbo' areas are showcased to prove the effectiveness of the developed methodology.

4.1.1 'Sala Vestibolo': 'Sala Vestibolo' is the entry room of Grotta Giusti cave system, providing access to both the thermal baths and diving area. It is a wide area, measuring about $50 \times 18$ meter in length and width, and $7 \mathrm{~m}$ in height. 'Sala Vestibolo' was surveyed with a Leica HDS7000 time-of-flight continuous wave TLS. About 10 scans were acquired (Fig. 4) with an average sampling step of $3 \mathrm{~mm}$ and aligned to produce a mesh $3 \mathrm{D}$ model, finally downsampled to $5 \mathrm{~cm}$ resolution in order to be smoothly used in virtual environments (Section 4.2). The highresolution geometric data could be used for other applications, such as mapping, documentation, etc. Some images were separately acquired to associate RGB information to the geometry measured with the TLS.

4.1.2 'Lago del Limbo': 'Lago del Limbo' is the entrance chamber for the diving experience in Grotta Giusti and it is connected to 'Sala Vestibolo' by a narrow corridor. It has an elongated shape, measuring about $20 \times 8 \times 17 \mathrm{~m}$, with a maximum water depth of about $10 \mathrm{~m}$. The chamber was surveyed with a stereo rig and with a DSLR camera.

The photogrammetric acquisitions performed with the stereo rig featured a two GoPro Hero4 Black Edition in their underwater pressure housings, an underwater light and two red laser pointers. The GoPro stereo rig (Fig. 5a) was preliminary calibrated (Fig. $5 \mathrm{~b}$ and $\mathrm{c}$ ), using rods and calibration devices previously measured in laboratory (Menna et al., 2013). The GoPro cameras were set in video mode and an automatic software synchronization algorithm was developed. The synchronization is based on the automatic localization in the recorded streams of common events, i.e. flashing lights visible in the videos and sounds audible in the audio channels.

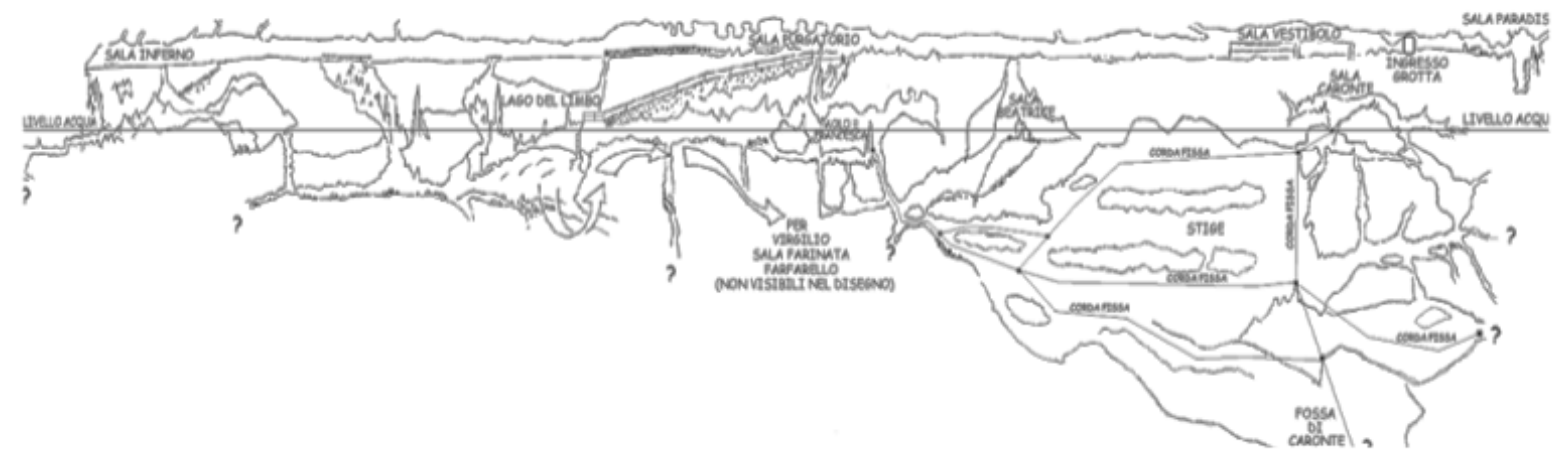

Figure 3. 2D map of Grotta Giusti (courtesy of Grotta Giusti diving center).
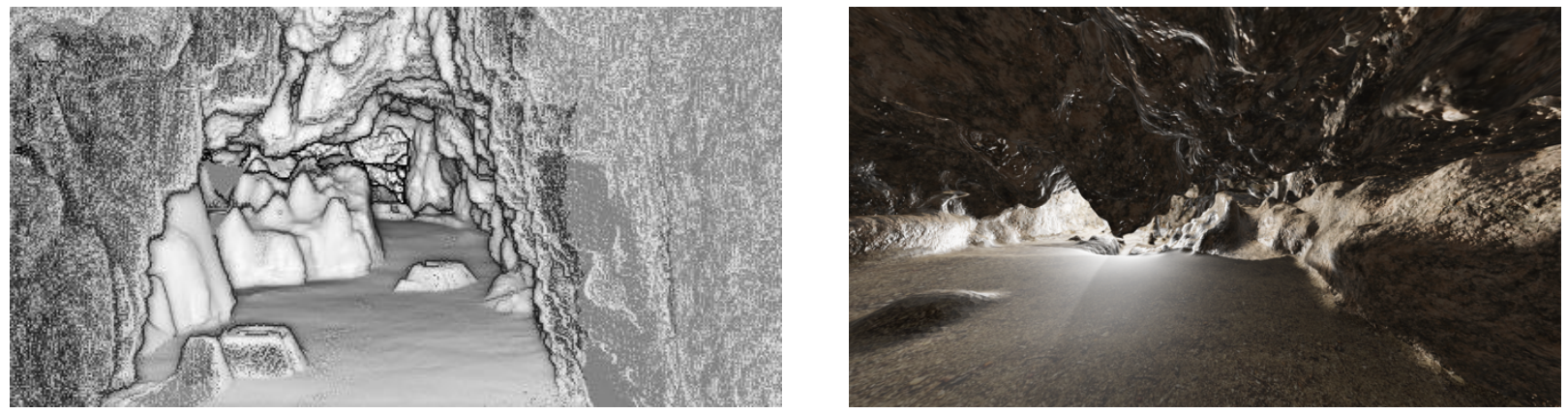

Figure 4. Rendered views of the 'Sala Vestibolo' point cloud surveyed with a TLS and textured with RGB images. 
a)

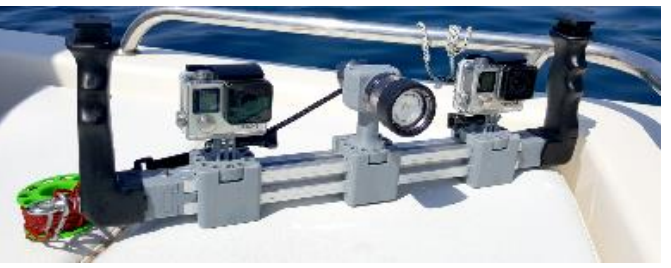

b)

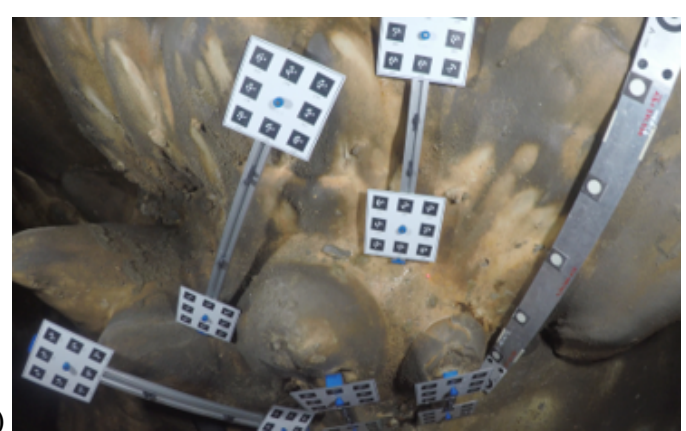

c)

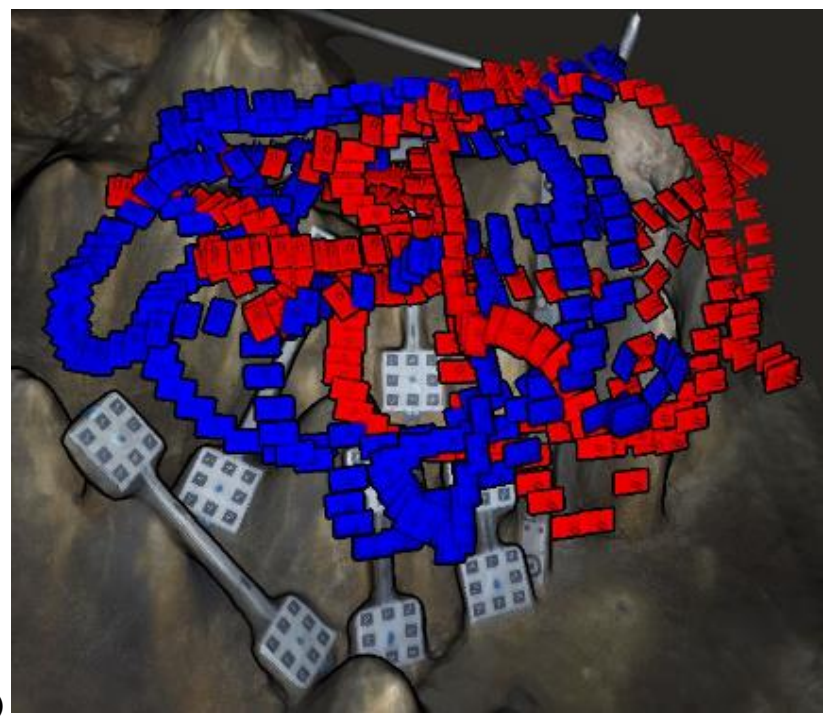

Figure 5. The assembled GoPRO stereo camera system (a); calibration area (testfield) set up in Grotta Giusti (b); camera network with in red and blue the camera right and left positions, respectively (c).

Light event is used for up-to-frame precise synchronization, while a further sub-frame precision can be achieved by using cross correlation matching of audio signals recorded by the two cameras. Details of the developed synchronization approach, as well as on the settings and pre-processing of the GoPro videos are reported in Nocerino et al. (2018) and Nocerino et al. (2013). The calibrated baseline was $33.5 \mathrm{~cm}$.

The laser pointers were collimated so that they intersect at the calibrated working distance of about $50 \mathrm{~cm}$. Their position and orientations with respect to the two cameras were also computed during the calibration stage providing an additional scaling information used as a cross check.

The calibrated stereo rig was used under and above-the-water to provide $3 \mathrm{D}$ scaled photogrammetric measurements of the two separate environments of the cave. Two strips above and five strips under the water with about $60-80 \%$ overlap were acquired. An innovative procedure was developed to jointly survey the submerged and emerged parts of the cave, relying on the use of the stereo system as link across the water level. Using the calibrated relative orientation constraints, a synchronized acquisition with a camera below and the other one above the water level proved to be an accurate and effective method for $3 \mathrm{D}$ modelling of semi-submerged environments. The calibration devices (Fig. 6a and b) were installed across the water level to assess the accuracy of the method. A similarity transformation was performed to rigidly align each rod to the corresponding one in photogrammetric reference system. The root mean square error (RMSE) of residuals of all five rods reached sub-centimeter accuracy in linking the above and below water 3D data (Fig. 6c). The rest of the chamber (parts far away from the water level, such as the ceiling) was photogrammetrically surveyed with a Nikon D750 in a NiMAR waterproof housing, coupled with a more powerful strobe unit. These data were useful to completely survey the area and provide a 3D model for visualization needs. The final merged (above and under the water) model of "Lago del Limbo" chamber is shown in Fig. 7. a)

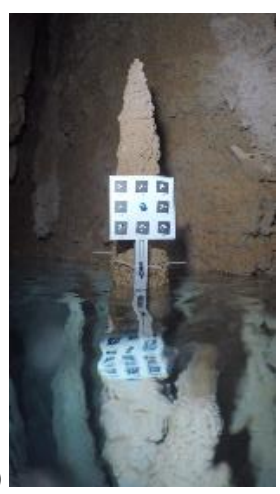

b)

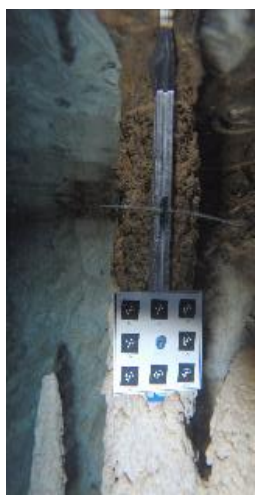

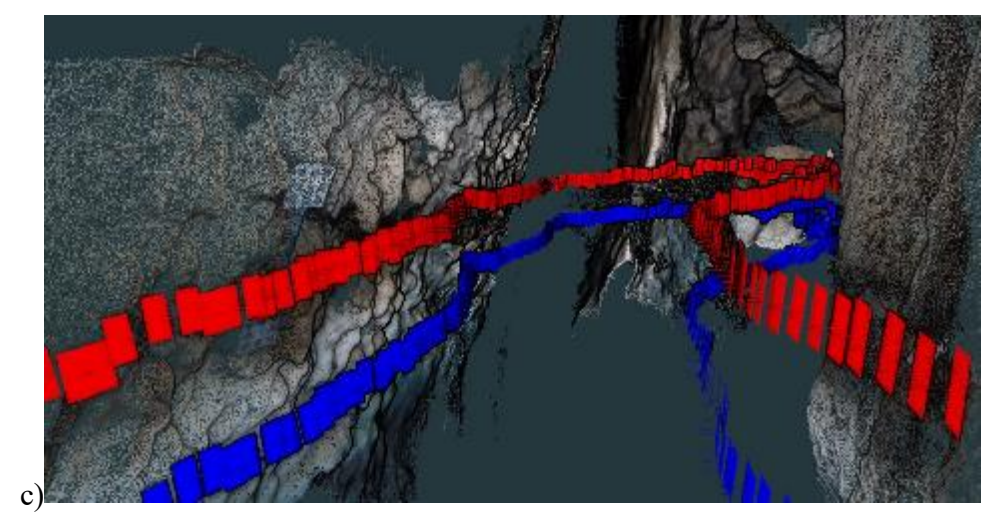

Figure 6. A calibration device seen from above (a) and below (b) the water cameras. Part of the network (and sparse point cloud) with the right (above the water - red) and left (underwater - blue) cameras of the stereo rig (c). 

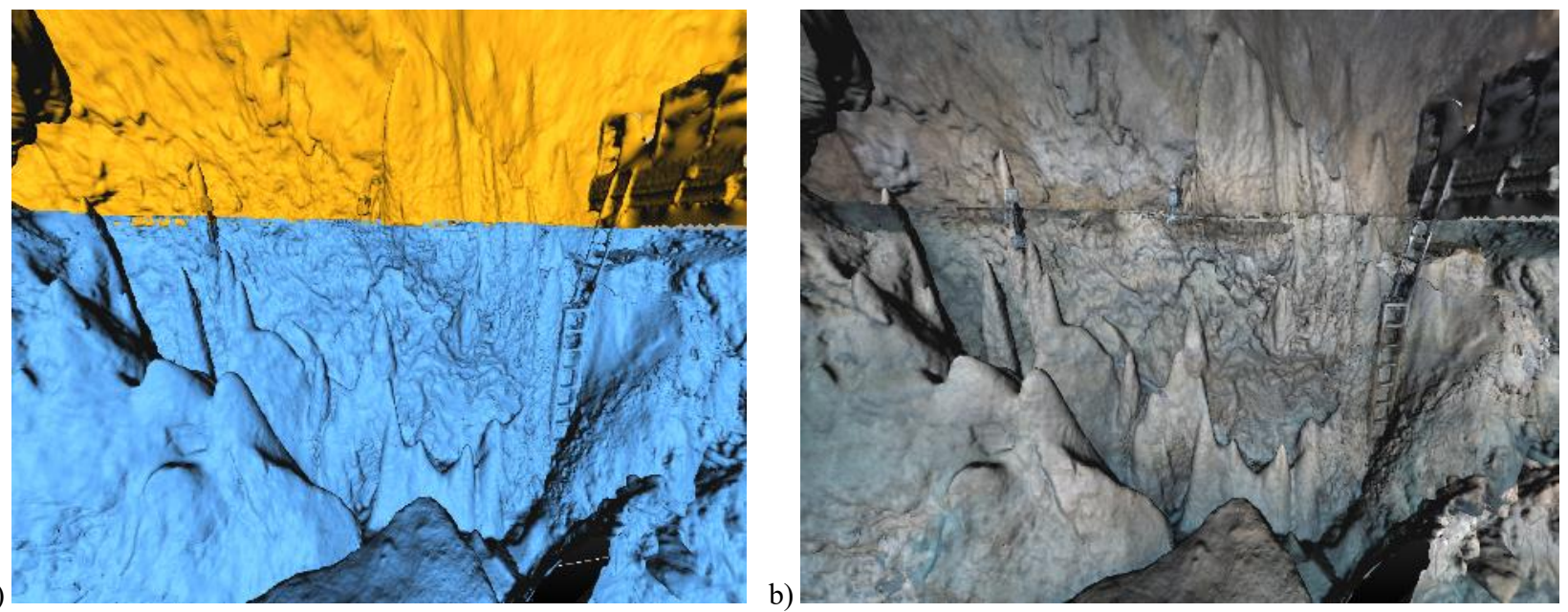

Figure 7. Final 3D mesh of "Lago del Limbo" (a) representing the above the water (yellow) and below the water (blue) parts. Final 3D textured mesh model (b), to be used in game engine tools to create virtual environments of the cave.

\subsection{Visualization}

For the visualization of the surveyed cave 3D models, an immersive virtual tour has been realized using Unity (https://unity.com/). Unity is a cross-platform game engine, heavily exploited in the $\mathrm{CH}$ field for serious games (Kontogianni et al., 2016; Mortara et al., 2014), virtual museums (Esmaeili et al., 2017; Kiourt et al., 2016), 3D/4D apps (Fritsch \& Klein, 2018) and virtual exploration of underwater sites (Bruno et al., 2018; Magrini et al., 2015). Unity allows an easy integration with virtual / augmented reality (VR/AR) frameworks.

In Unity, the level of immersivity and the navigation within the virtual world are decided during the construction of the scenes. In the virtual tour of Grotta Giusti, each scene allows the users to virtually visualize part of the surveyed 3D models in a complete immersive way. The 3D geometric models were sampled at $5 \mathrm{~cm}$ and textured with high-resolution images. This is a typical approach in VR/AR applications, where most visual details are provided by imagery and not by geometry.

The complete immersion in the scene increases the sense of presence in the virtual environment and allow a better visualization of every detail of the underground structures. The realized virtual environment of the cave system, as a virtual tour of panoramic images produced from the textured 3D model, can be accessed at http://3dom.fbk.eu/repository/grottagiusti/.

\section{DISCUSSION AND FUTURE WORKS}

The paper provided an overview of the technical and procedural steps undertaken for the realization of a feasibility study aimed at the 3D virtualization of Grotta Giusti, a complex cave system in central Italy, at the date only partially mapped with traditional methods consisting of distance, azimuth and depth measurements. The full 3D modelling of a cave whose parts extend across the water level is still an unsolved task which cannot be easily accomplished with standard surveying equipment. In particular, Grotta Giusti cave environment is characterised by unfavourable conditions for optical instruments, mainly caused by high relative humidity. Indeed, air stratification with different temperatures between the upper and lower chambers implies a careful acquisition plan in order to let the instrument to acclimate and avoid condensation phenomena over the optics. For example, during the tests, the Leica HDS7000 TLS, available at the moment of the test, was at the limit of usability due to its IP53 rating, which is not suited for saturated environments. Also, wet and smooth surfaces cause artefacts in both laser scanning and photogrammetric point cloud due to specular reflections. Besides the environmental conditions, with respect to not flooded parts of Grotta Giusti, the most critical parts to survey from a geometric point of view corresponded to the ceiling of the cave, often very far from the ground level, in particular when stalactites were present. In these cases, the laser scanning technique seemed to have a greater advantage over the photogrammetric one due to the several shadows in the captured data caused by self-occlusions and to the small baseline to distance ratio for photogrammetric measurements. Indeed, TOF laser scanning, being an active technique with coaxial laser emitter and sensor, does not necessitate multiple viewpoints to capture the 3D information and does not necessitate external lighting. At the same time the use of monochromatic laser light does not provide colour information about the surveyed part and a photogrammetric acquisition is anyway necessary.

The link between under and above the water surveys was demonstrated using an experimental technique based on a precalibrated stereo camera rig. The accuracy assessment in aligning the above and below the water 3D model was carried out using calibration devices mounting a target plate below and one above the water. Sub centimeter accuracy was achieved during the test in the confined area of 'Lago del Limbo'. An accuracy assessment investigation will be in the future extended to larger areas.

Digital cameras in the underwater pressure housings proved to be very practical also for surveying dry parts accessible only after diving (syphons). Multimedia effects of the additional optical elements represented by the housing port (either flat or dome) over the final accuracy of the 3D model would deserve a deeper investigation, currently missing in the scientific literature. Future developments will include the use of a handheld mobile mapping laser scanner (Nocerino et al., 2017, 2019) in such complex environments.

The developed VR application is an attempt to providing to a vast public an explorable and immersive, accurate and photorealistic virtualized model of Grotta Giusti, preserving and conveying its heritage value.

\section{ACKNOWLEDGEMENTS}

The authors are thankful to Luciano Tanini and the team of the Grotta Giusti diving center, who strongly believed in the virtualization project of Grotta Giusti and enthusiastically supported the measurement campaign. 


\section{REFERENCES}

Alessandri, L., Baiocchi, V., Del Pizzo, S., Rolfo, M.F. and Troisi, S., 2019. Photogrammetric Survey with Fisheye Lens for the Characterization of the la Sassa Cave. ISPRS-International Archives of the Photogrammetry, Remote Sensing and Spatial Information Sciences, 422, pp.25-32.

am Ende, B.A., 2001. 3D mapping of underwater caves. IEEE Computer Graphics and Applications, 21(2), pp.14-20.

Apollonio, F.I., Gaiani, M. and Sun, Z., 2017. A reality integrated BIM for architectural heritage conservation. In Handbook of research on emerging technologies for architectural and archaeological heritage, pp. 31-65. IGI Global.

Bartz, D., 2003. Large model visualization: techniques and applications.

Bekele, M.K., Pierdicca, R., Frontoni, E., Malinverni, E.S. and Gain, J., 2018. A survey of augmented, virtual, and mixed reality for cultural heritage. Journal on Computing and Cultural Heritage (JOCCH), 11(2), p.7.

Bruno, F., Lagudi, A., Barbieri, L., Muzzupappa, M., Mangeruga, M., Cozza, M., Cozza, A., Ritacco, G. and Peluso, R., 2017. Virtual Reality Technologies for the Exploitation of Underwater Cultural Heritage. In "Latest Developments in Reality-Based 3D Surveying and Modelling" Remondino, F., Georgopoulos, A., González-Aguilera, D., Agrafiotis, P., Eds, pp. 220-236.

Bussotti, S., Di Franco, A., Bianchi, C.N., Chevaldonné, P., Egea, L., Fanelli, E., Lejeusne, C., Musco, L., Navarro-Barranco, C., Pey, A. and Planes, S., 2018. Fish mitigate trophic depletion in marine cave ecosystems. Scientific reports, 8 .

Clark, C., M., Olstad, C., S., Buhagiar, K. and Gambin, T., 2008. Archaeology via underwater robots: Mapping and localization within maltese cistern systems. Proc. IEEE 10th Int. Conference on Control, Automation, Robotics and Vision, pp. 662-667.

De Waele, J., Fabbri, S., Santagata, T., Chiarini, V., Columbu, A. and Pisani, L., 2018. Geomorphological and speleogenetical observations using terrestrial laser scanning and 3D photogrammetry in a gypsum cave (Emilia Romagna, N. Italy). Geomorphology, 319, pp.47-61.

Drap, P., Merad, D., Boï, J.M., Mahiddine, A., Peloso, D., Chemisky, B., Seguin, E., Alcala, F. and Bianchimani, O., 2014. Underwater multimodal survey: Merging optical and acoustic data. In Underwater Seascapes, pp. 221-238. Springer, Cham.

Esmaeili, H., Thwaites, H. and Woods, P.C., 2017. Workflows and Challenges Involved in Creation of Realistic Immersive Virtual Museum, Heritage, and Tourism Experiences: A Comprehensive Reference for 3D Asset Capturing. $13^{\text {th }}$ IEEE International Conference on Signal-Image Technology \& Internet-Based Systems (SITIS), pp. 465-472.

Fabbri, S., Sauro, F., Santagata, T., Rossi, G. and De Waele, J., 2017. High-resolution 3-D mapping using terrestrial laser scanning as a tool for geomorphological and speleogenetical studies in caves: An example from the Lessini mountains (North Italy). Geomorphology, 280, pp.16-29.
Fritsch, D. and Klein, M., 2018. Design of 3D and 4D Apps for Cultural Heritage Preservation. In Digital Cultural Heritage, pp. 211-226. Springer, Cham.

Garland, M., 1999. Multiresolution modeling: Survey \& future opportunities. State of the art report, pp.111-131.

Gerovasileiou, V., Trygonis, V., Sini, M., Koutsoubas, D. and Voultsiadou, E., 2013. Three-dimensional mapping of marine caves using a handheld echosounder. Marine Ecology Progress Series, 486, pp.13-22.

Gustafsson, C., 2015. Conservation 3.0 inclusive sustainable an innovative conservation in the Age of Smart Specialisation Strategies,

https://campusnackrosen.gu.se/digitalAssets/1556/1556489 gus tafsson-h--gre-seminarium-19-november-2015.pdf. Accessed June 2019.

Iliffe, T., M. and Bowen, C., 2001. Scientific cave diving. Marine Technology Society Journal, 35(2), pp.36-41.

Kincaid, T.R., 2000, Three Dimensional Geometric Modeling and Visualization of Phreatic Karst Caves with Implications for Hydrologic and Geomorphic Studies, in: Sasowsky, I.D. and Wicks, C.M. (eds.), Groundwater flow and contaminant transport in carbonate aquifers: A.A. Balkema, Rotterdam, p.169-190.

Kiourt, C., Koutsoudis, A., Markantonatou, S. and Pavlidis, G., 2016. The 'Synthesis' Virtual Museum. Mediterranean Archaeology \& Archaeometry, 16(5).

Kontogianni, G., Koutsaftis, C., Skamantzari, M., Georgopoulos, A. and Chrysanthopoulou, C., 2016. Developing and Exploiting 3D Textured Models for a Serious Game Application. 8th IEEE International Conference on Games and Virtual Worlds for Serious Applications (VS-GAMES), pp. 1-4.

Lauritzen, S.E., Abbott, J., Arnesen, R., Crossley, G., Grepperud, D., Ive, A. and Johnson, S., 1985. Morphology and hydraulics of an active phreatic conduit. Cave Science, 12(3), pp.139-146.

Leshikar-Denton, M., E. and Erreguerena, P., L., 2016. Underwater and maritime archaeology in Latin America and the Caribbean, Vol. 56, Routledge.

Magrini, M., Pascali, M.A., Reggiannini, M., Salvetti, O. and Tampucci, M., 2015. Virtual Immersive Environments for Underwater Archaeological Exploration. Proc. IMTA, pp. 53-57.

Mallios, A., Ridao, P., Ribas, D., Carreras, M. and Camilli, R., 2016. Toward autonomous exploration in confined underwater environments. Journal of Field Robotics, 33(7), pp.994-1012.

Mattes, J., 2015. Underground fieldwork - A cultural and social history of cave cartography and surveying instruments in the 19th and at the beginning of the 20th century. International Journal of Speleology, 44(3), pp. 251-266.

Menna, F., Nocerino, E., Troisi, S. and Remondino, F., 2013, May. A photogrammetric approach to survey floating and semisubmerged objects. In Videometrics, Range Imaging, and Applications XII, SPIE Vol. 8791, p. 87910H.

Mohammed Oludare, I. and Pradhan, B., 2016. A decade of modern cave surveying with terrestrial laser scanning: A review 
of sensors, method and application development. International Journal of Speleology, 45(1), p.8.

Moisan, E., Charbonnier, P., Foucher, P., Grussenmeyer, P., Guillemin, S. and Koehl, M., 2015. Adjustment of sonar and laser acquisition data for building the 3D reference model of a canal tunnel. Sensors, 15(12), pp.31180-31204.

Moisan, E., Heinkele, C., Charbonnier, P., Foucher, P., Grussenmeyer, P., Guillemin, S. and Koehl, M., 2017. Dynamic 3D modeling of a canal-tunnel using photogrammetric and bathymetric data. The International Archives of Photogrammetry, Remote Sensing and Spatial Information Sciences, 42, p.495.

Mortara, M., Catalano, C.E., Bellotti, F., Fiucci, G., HouryPanchetti, M. and Petridis, P., 2014. Learning cultural heritage by serious games. Journal of Cultural Heritage, 15(3), pp.318325 .

NOAA, 2018. How much of the ocean have we explored? National Ocean Service website, https://oceanservice.noaa.gov/facts/exploration.html. Accessed June 2019.

Nocerino, E., Nawaf, M.M., Saccone, M., Ellefi, M.B., Pasquet, J., Royer, J.P. and Drap, P., 2018. Multi-camera system calibration of a low-cost remotely operated vehicle for underwater cave exploration. International Archives of the Photogrammetry, Remote Sensing \& Spatial Information Sciences, 42(1).

Nocerino, E., Menna, F., Remondino, F., Toschi, I. and Rodríguez-Gonzálvez, P., 2017. Investigation of indoor and outdoor performance of two portable mobile mapping systems. Proc. Videometrics, Range Imaging, and Applications XIV, SPIE Vol. 10332, p. 103320I.

Nocerino, E., Rodríguez-Gonzálvez, P., Menna, F, 2019. Introduction to mobile mapping with portable systems. ISPRS Book Series, R. Lindenbergh \& R. Belen (Eds.). CRC Press (in press).

Nocerino, E., Menna, F. and Troisi, S., 2013. High accuracy lowcost videogrammetric system: an application to 6DOF estimation of ship models. In Videometrics, Range Imaging, and Applications XII; and Automated Visual Inspection (Vol. 8791, p. 87910J). International Society for Optics and Photonics.

Potenziani, M., Callieri, M., Dellepiane, M., Corsini, M., Ponchio, F. and Scopigno, R., 2015. 3DHOP: 3D heritage online presenter. Computers \& Graphics, 52, pp.129-141.

Rahman, S., Li, A.Q. and Rekleitis, I., 2018, May. Sonar Visual Inertial SLAM of underwater structures. Proc. IEEE International Conference on Robotics and Automation (ICRA), pp. 1-7.

Richmond, K., Flesher, C., Lindzey, L., Tanner, N. and Stone, W.C., 2018, October. SUNFISH ${ }^{\circledR}$ : A human-portable exploration AUV for complex 3D environments. In OCEANS 2018 MTS/IEEE Charleston (pp. 1-9). IEEE.

Rodríguez-Gonzálvez, P., Nocerino, E., Menna, F., Minto, S. and Remondino, F., 2015. 3D surveying \& modeling of underground passages in WWI fortifications. International Archives of the Photogrammetry, Remote Sensing \& Spatial Information Sciences, Vol. 40(5/W4), pp. 17-24.
Rosso, A., Gerovasileiou, V., Sanfilippo, R. and Guido, A., 2018. Undisclosed biodiversity of submarine caves of the Aegean sea (eastern Mediterranean). Proc. 2nd Mediterranean Symposium on the conservation of Dark Habitats (p. 47).

Perfetti, L., Polari, C. and Fassi, F., 2017. Fisheye photogrammetry: tests and methodologies for the survey of narrow spaces. Int. Archives of the Photogrammetry, Remote Sensing and Spatial Information Sciences, 42(W3), pp.573-580.

Pukanská, K., Bartoš, K., Bella, P. and Sabová. J., 2017. Comparison of non-contact surveying technologies for modelling underground morphological structures. Acta Montanistica Slovaca 22, no. 3 .

Sammartano, G. and Spanò, A., 2018. Point clouds by SLAMbased mobile mapping systems: accuracy and geometric content validation in multisensor survey and stand-alone acquisition. Applied Geomatics, 10(4), pp.317-339.

Stasinopoulou, T., Bountouri, L., Kakali, C., Lourdi, I., Papatheodorou, C., Doerr, M. and Gergatsoulis, M., 2007. Ontology-based metadata integration in the cultural heritage domain. In International Conference on Asian Digital Libraries (pp. 165-175). Springer, Berlin, Heidelberg.

Techopedia, 'What does Data Virtualization mean?' https://www.techopedia.com/definition/1007/data-virtualization. Accessed, June 2019.

The Wakulla 2 expedition, 1988. The US Deep Caving Team, Inc. http://www.usdct.org/wakulla2.php. Accessed June 2019.

Tommasi, C., Fiorillo, F., Jiménez Fernández-Palacios, B. and Achille, C., 2019. Access and Web-Sharing of 3D Digital Documentation of Environmental and Architectural Heritage. ISPRS Int. Archives of the Photogrammetry, Remote Sensing and Spatial Information Sciences, 42-2/W9, pp. 707-714.

Weidner, N., 2017. Underwater Cave Mapping and Reconstruction Using Stereo Vision. https://scholarcommons.sc.edu/cgi/viewcontent.cgi?article=536 9\&context=etd. Accessed June 2019.

White, C., Hiranandani, D., Olstad, C.S., Buhagiar, K., Gambin, T. and Clark, C.M., 2010. The Malta cistern mapping project: Underwater robot mapping and localization within ancient tunnel systems. Journal of Field Robotics, 27(4), pp.399-411.

Zlot, R. and Bosse, M., 2014. Three-dimensional mobile mapping of caves. Journal of Cave \& Karst Studies, 76(3). 